\title{
11. COMMISSION DES COUCHES EXTERIEURES DU SOLEIL
}

Président: C. W. Allen.

Membres: MM. Abetti, Blackwell, Blaha, Bogorodsky, Brahde, Mme Brück, MM. Bruzek, Cardus, Coutrez, Das, Mme d'Azambuja, M. L. d'Azambuja, Mme Dodson-Prince, MM. Dollfus, dos Reis, Ellison, J. W. Evans, Giovanelli, Gnevyshev, Goldberg, Gullón, Kiepenheuer, Krat, Kristenson, Krook, McMath, Macris, Miyamoto, Mohler, R. Müller, Mustel, Narayan, Nicholson, Notuki, Ohman, Parker, Petri, Pettit, Pikelner, Rahman, Richardson, Roberts, Rösch, Saha†, Severny, Shklovsky, Suemoto, Svestka, Thomsen, Trellis, Unsöld, van de Hulst, Vyazanitsyn, Waldmeier, Wayman, Zanstra.

\section{II a. SOUS-COMMISSION DE CINÉMATOGRAPHIE DES PHÉNOMENES CHROMOSPHÉRIQUES}

Président: W. O. Roberts.

Membres: MM. L. d'Azambuja, Gnevyshev, McMath, Severny, Waldmeier.

\section{GENERAL}

The work of Commission II touches very closely on that of several other Commissions such as I0, I2, I3, 40 and the Mixed-Commission on solar-terrestrial relations. Where a subject is of interest to Commission II, but is thought more closely related to another Commission it has not normally been included in the following report. Thus white-light solar phenomena are left to Commission Io (with faculae marginal), purely spectroscopic matters and the reversing layer to Commission I2, and descriptive eclipse observations to Commission 13. However physical interpretations of the chromosphere and corona resulting from eclipse observations are included as a Commission II concern. Solar radio observations and solar-terrestrial relations are included only in so far as they bear on the physical study of the chromosphere and corona. The observations and coordination of fast moving chromospheric phenomena are dealt with by Sub-commission II $a$.

Since the last General Assembly the work of our Commission has been stimulated by preparation for and participation in the I.G.Y. Many new instruments have been set up and close co-operation in observing programmes has been put into effect.

\section{EQUIPMENT}

The main technical advances concern the development of instruments that were already under way in I955. There have been: (a) an increase in the number, variety and scope of bi-refringent filters used for both chromospheric and coronal studies; $(b)$ the development of high resolution grating spectrographs now fed by coronagraphs and used for chromospheric as well as photospheric work; (c) further development of the Lyot photo-electric coronameter; $(d)$ improvement in means to detect electrons in the faint outer corona; and $(e)$ devices to facilitate special observations, calibrations, guiding, and rapid repetition of slightly varying observations.

An excellent recent review of the instrumental situation has been made by $\mathrm{W}$. $\mathrm{O}$. Roberts [x], and therefore it is only necessary to summarize points of interest.

More than 50 bi-refringent narrow band $(<I \AA)$ filters have been put into use for chromospheric studies; most of these are in $\mathrm{H} \alpha$, but some are available for $\mathrm{D}_{3}$ of $\mathrm{He}$ and $\mathrm{H}, \mathrm{K}$ of $\mathrm{Ca}^{+}$. Many with an $0.7 \AA$ band pass have been built by Optique et Précision de Levallois (Paris), and seven orders are placed for the SECASI (Bordeaux) instrument of standardized design (due to Lyot) suited to automatic flare patrol. Some of these are going into use. Some of the variations from the standard form are as follows: $(a)$ a filter 


\section{COUCHES EXTERIEURES DU SOLEIL}

by Solc [2] with only two polaroids and several plates of the same thickness; $(b)$ a filter by Öhman (3) based on the rotation of polarization of spectrum lines in a magnetic field; $(c)$ split-element filters by Dunn [1] and by Öhman; $(d)$ high transparency and wide-angle filters for the corona by Dollfus [4]; (e) narrow tunable band filter ( $\frac{1}{8} \AA$ over $\pm I 6 \AA$ ) by Giovanelli at Sydney.

The spectacular high dispersion vacuumated spectrograph of the McMath-Hulbert Observatory [s] (resolution 660000 ) has foreshadowed instruments with similar dispersion at Cambridge (England) and the Crimea Observatory. The McMath spectrograph has been used for direct photo-electric isophotometry of spectrum lines [6]. At Sacramento Peak a high dispersion spectrograph has been attached to a coronagraph. Spectrographs with wide wave-length ranges to cover complete flare or prominence spectra are being set up at Pic-du-Midi, Göttingen, and McMath Observatory.

In the coronameter, invented by Lyot in I950, the intensity of the coronal line is compared photo-electrically with light of a nearby wave-length. The instrument is so sensitive that the corona can be detected through poor skies. An instrument of this type made at Meudon with the support of an I.A.U. subvention of $\$ 2000$ is now (I957) being tested and will probably be in service at the time of the Moscow meeting. A somewhat similar instrument, but with a spectrograph replacing a bi-refringent filter, is in use at Sacramento Peak.

Ultra-sensitive photo-electric polarimeters have been devised and used with coronagraphs to detect very faint $\mathrm{K}$-Corona $[7,8]$. Such instruments have detected coronal electrons more than one radius from the Sun's limb.

Of the smaller devices, so necessary to observational progress, we might mention: (a) Ohman's flare-brightness photometer [3]; $(b)$ a rapid sequence coronal spectrograph analogous to Delandres' velocity recorder [9]; (c) bi-refringent guiders, used at both Climax and Crimea; $(d)$ double or multiple camera spectrographs for comparing different lines, used at Meudon and Ondrejov; and $(e)$ television and photo-electric recording systems $[\mathrm{ro}, \mathrm{n}]$.

\section{INTERNATIONAL CO-OPERATION, REGULAR AND SYNOPTIC PUBLICATIONS}

The normal world-wide co-operation in pooling and publishing observations of the Sun's outer layers is being overshadowed at the present time by intense I.G.Y. activity. Detailed information on observations being made, co-operating observatories and organization for the dissemination of the information is best found in the I.G.Y. publication $[\mathbf{2} 2, \mathbf{3} 3]$.

The regular observational material published by various observatories at the time of the Dublin Meeting is set out in the last report [14]. The publications from Kodaikanal and Catania could also have been included. Several changes and additions have been made since the last Meeting but it is not certain how these will continue after the end of 1958 , i.e. at the close of the I.G.Y. The following additional publications have appeared: Meudon Cartes Journalières de l'Activité Solaire containing chromospheric and coronal data obtained in France; Fraunhofer Institut Daily Maps of the Sun containing similar data but selected from about a dozen stations with a world-wide distribution; U.S.S.R. Academy Solnechnye Dannye containing Russian data in a somewhat similar form; Documentation des Observateurs Série Solaire containing monthly synoptic maps, somewhat similar to those of Tokyo, Meudon, and Zürich, derived from observations at Kanzelhöhe, Graz; Central Radio Propagation Laboratory Solar-Geophysical Data with coronal emission indices, plage data, flare lists, as well as geomagnetic, radio and sunspot data.

The Meudon Cartes Synoptiques de la Chromosphere Solaire, for which an annual subvention of 2700 gold francs has been made by the I.A.U., is published in vol. II, fasc. I to the end of I947. Fasc. II containing I948-49-50 is in press (mid-I957) and should be distributed before the end of I957. Fasc. III containing I95I-52-53-54 is in preparation and should be distributed by mid-I958. 


\section{COMMISSION 11}

Details and assemblies of past Coronal results (from about I940) are being published by individual observatories. The Pic-du-Midi observations are to appear in a work by Trellis in Ann. Astrophys., and synoptic charts of the data are in press. The Arosa data are set out in Waldmeier's Die Sonnenkorona.

The increase of solar activity and also the distribution of several monochromatic filters and automatic heliographs have resulted in a very great increase in the number of flares reported to the Quarterly Bulletin. We might compare the I 895 flares reported in I956 with I245 which was the greatest number in any year of the preceding sunspot maximum. It is anticipated that fifty-four stations will co-operate for flare observations during the I.G.Y. and that at any moment of the day at least six stations should be observing.

Although several estimates have been made of the absolute coronal scale $[15,16]$ it is not considered that the scale, and the inter-agreement of the various observers, is yet good enough to justify synthesizing the coronal line intensity measurements into one daily result. Such a reduction would be a considerable convenience for the Quarterly Bulletin and would make the results much more suitable for consistent use.

\section{FACULAE, PLAGES}

It has often been suggested that sunspot numbers or areas are not the most satisfactory data for correlation with radiation in the decimetre band or in the ionospheric ultraviolet. Faculae and plages appear by their greater area, longer life and general appearance to be more nearly associated with the regions emitting the above radiations. Quantitative tests call for systematic measurement of faculae and plage areas and brightness, but such observations are not easy and no entirely satisfactory data have yet been obtained. Of white light faculae the data from Greenwich can probably not be improved. Of Ca plages $\left(\mathrm{K}_{232}\right)$ the data by Dodson [17] are probably the best that exist, but the systematic material is not published. The photo-electric plage measurements of Kiepenheuer [18] at Capri $(G)$ in $\mathrm{K}_{3}$ are most promising. The bright $\mathrm{H} \alpha$ and $\mathrm{Ca}$ flocculi indices used for so many years do not appear to be well suited to quantitative correlations. This is mainly because the indices are not additive and therefore show no proportionality with the radiations to be correlated.

\section{CHROMOSPHERE}

In the period since the last report observational work giving information on the chromosphere has come from tower telescopes [19,20,2r] and coronagraphs [22] as well as from eclipses. Most of the observations and their interpretation have been aimed at making progress with the difficult question of the physical conditions in the chromosphere.

Estimates of kinetic temperature from line profiles are inclined to differ as a result of the rather doubtful correction for extraneous effects. Published results [20, 21, 22, 23 24, 25] range from 6000 to $55000^{\circ} \mathrm{K}$ but most values are close to Io $000^{\circ} \mathrm{K}$. Parker [21] finds different temperatures for different atoms. For excitation temperatures we have: $4500^{\circ} \mathrm{K}$ for $\mathrm{CN}$ bands [26]; $4610^{\circ} \mathrm{K}$ for $\mathrm{C}_{2}$ bands [21]; 7000 to $4500^{\circ} \mathrm{K}$ for $\mathrm{CN}$ bands [27]; 6000 to $20000^{\circ} \mathrm{K}$ from $\mathrm{H} \alpha$ lines [28]; $6000^{\circ}$ from L $\alpha$ [29]; and $3800^{\circ}$ for iron lines [30]. High values for $\mathrm{O} I$ have been explained by a coincidence [31]. De Jager's summary [32] puts the low chromosphere temperature between 5000 and $10000^{\circ} \mathrm{K}$.

Measurements of kinetic temperature are closely bound up with the turbulent velocity which is difficult to isolate. Estimates of the most probable turbulent velocity $\xi_{[21,23]}$ from measurements, and a discussion of such results [32], indicate a turbulence rising from $\xi=2 \mathrm{~km} / \mathrm{sec}$ at the base of the chromosphere to about $\xi=\mathrm{r} 5 \mathrm{~km} / \mathrm{sec}$ near a height of $2500 \mathrm{~km}$. Other values obtained, $19.5 \mathrm{~km} / \mathrm{sec}[25], 6-20 \mathrm{~km} / \mathrm{sec}[20]$, and $I 6.7 \mathrm{~km} / \mathrm{sec}[33]$ are in reasonable agreement.

Other (non-eclipse) chromospheric observations are concerned with: the life and size of spicules and flocculi [34]; radial and tangential velocity shifts in the $\mathrm{Ca}^{+}$lines $\mathrm{K}_{2}$ and $\mathbf{K}_{3}[35]$; the mottles of hydrogen spectrograms (and their interpretation) [32]; spicules [36] and their statistics [37]; and the chromosphere $\mathrm{H} \alpha$ and $\mathrm{D}_{3}$ heights in various latitudes [38]. 


\section{COUCHES EXTERIEURES DU SOLEIL}

There have been extensive and vigorous efforts to devise chromospheric models that can reproduce observational results. Models based on thermal equilibrium varying with height only are obviously over-simplified and the two elaborations most likely to produce realistic results are: $(a)$ to allow for the difference between kinetic, excitation, and radiation temperatures, and $(b)$ to introduce 'hot' and 'cold' columns to allow for inhomogeneity. The physical study of non-thermal equilibrium had been developed earlier by Thomas [39] and Giovanelli [40]. These results are now applied to chromospheric problems $[37,41,42,43]$, the general conclusion being that electron temperatures are significantly greater than excitation temperatures which vary for each atomic level. Models containing both hot and cold columns have been proposed by Athay and others $[28,37]$ who consider the spicules to be represented by cold columns. Another elaboration that has influenced chromospheric models is the recognition of regions of stability and instability based on the relation of energy emission and energy input $[28,37]$. The uncertainty of these elaborations justifies their omission for some purposes and models from a simpler point of view still have a place. The models for the low chromosphere [30], and the high transition (to corona) layer [44] can be considered in this category. There is not yet enough agreement between the various models to justify attempting a representative mean.

Theoretical studies have been directed towards the integral equations whereby the source function can be interpreted from L $\alpha$ observations [45], and chromospheric electrical conductivity [46].

\section{FLARES AND ASSOCIATED ACTIVITY}

The intensive observations of flares and their neighbourhood in the last few years have revealed interesting features, some of which are normal to flares and some exceptional [47]. Great attention has been paid, particularly by Severny [48], to the very small rather short-lived low-level phenomena that have been called 'bombs' and 'moustaches'. Studies of the line-broadening, asymmetry and continua of these phenomena give evidence of explosions with $1000 \mathrm{~km} / \mathrm{sec}$ velocities, nuclear generation with production of deuterium and $\mathrm{IO}^{9} \mathrm{eV}$ particles. There is considerable support for earlier suggestions of relativistic electrons, etc. [49]. The development of spectrographs with very high dispersion together with optical systems with a low light-scatter promises considerable improvement in linestructure problems $[50,3 x]$.

Detailed recording and photometry of many flares [52] show them to be of two types: (a) the rarer and more vigorous, which have a vertical motion with the flare streaming towards the leading spot at $300 \mathrm{~km} / \mathrm{sec}$, and $(b)$ static flares. Photometric flare observations have been compared in detail with geophysical data [53], and studies of their slope size and influence have given indications of flare height $[54,55]$. There is now extensive material for extracting solar activity information from flare statistics $[56,57,58]$.

Fortune has met the rocket observers who have now taken observations during a flare and found [59], as many had expected, that X-rays of about $3 \AA$ were emitted. The rare phenomenon of a white-light emission spot was observed in the flare of 23 February I 956 [60].

The aim of several researches has been to determine physical conditions within a flare, and an extensive study of normal flares has been made [57]. Representative values are: electron temperature $T_{2}$ (deep in a flare) $\simeq 9000^{\circ} \mathrm{K}$, electron density $N_{\epsilon} \simeq 10^{13} \mathrm{~cm}^{-3}$. A quite exceptional limb flare [6r] led to $T_{e}=30000^{\circ} \mathrm{K}$ and $N_{e}<3 \times 10^{12} \mathrm{~cm}^{-3}$.

More theories of flare mechanism are available but none can yet be regarded as established. Some recent suggestions are: that a surge prominence can be violently reflected back on itself by a magnetic field [62]; that a gas which is partly ionized (thus defining the flare level) can extract high energy from hydromagnetic waves [63]; that magnetic energy can be released at a neutral point [ ${ }^{4} 4$ ] (it is noted in this connexion [65] that flares coincide with the loci of magnetic polarity changes); that the Fermi mechanism [66] can account for relativistic energies of ions (cosmic rays) and also for the flare continuum and the quantity of energy involved [67]. 


\section{COMMISSION 11}

\section{PROMINENCES AND FILAMENTS}

There have been extensive detailed observations of both the spectra and direct images of prominences.

Investigations of spectrum line-widths lead to kinetic temperatures near $10000^{\circ} \mathrm{K}$ for quiescent prominences $[68,69,70,71,72]$ and values increase to $50000^{\circ} \mathrm{K}$ for active prominences [73,74]. Most probable turbulent velocity estimates are about $9 \mathrm{~km} / \mathrm{sec}$ for quiet prominences $[68,70,71]$ and of course much higher for those moving violently [75].

Many individual prominences have been studied in detail because of some particular point of interest $[76,77,78,79,80]$. Intensity contours have been made [81] and the relation between prominences as seen in different spectrum lines studied [82]. The solar rotation law has been brought into a simpler form $\left[8_{3}\right]$ by noting that prominence motion towards the pole is due to growth along the filaments. The rate of this movement is independent of maximum sunspot number [84].

It has been increasingly evident that the motions of prominences are governed to a large extent by the magnetic fields of the Sun's outer layers. When prominence motions are fitted to a dipole field the effective depth of the dipole in an active region has been found $\left[8_{5}\right]$ to be about $0.2 r_{\odot}$. If magnetic fields are to support stable prominences the fields must be horizontal [8o] and preferably have a dip at the point where the prominence is lodged. Magnetic fields do not account very readily for the small faint moving closed loops that have been observed recently [86]. Attempts have been made to determine the mean magnetic fields by studying the internal motions of active prominences [75].

A fairly satisfactory equation for the heat gains and losses has been found [87] but seems to apply to quiescent prominences only. However the mechanism differs so greatly from the earlier Joule loss mechanism [88] that all such suggestions must be regarded as tentative. An explanation of the cooling down of coronal matter to form the rain type of prominence has also been offered [89]. The part played by the hydrogen molecule in lowtemperature prominences has been investigated [9o].

\section{CORONA}

Coronal observing is a continual battle against extraneous light and many devices have been used to reduce the unwanted light-scatter or increase the detectability of the wanted corona. Recent methods include : use of the infra-red $[91,92,93]$; use of aircraft $[91,93]$; masking devices $[93,94]$; and detection devices [x].

After reducing the scatter and making appropriate corrections, the coronal brightness can lead to values for the coronal electron density $N_{\text {. }}$. New investigations have generally $[92,93,94,95]$, but not always [96], led to higher values than those of a few years ago [97]. Estimates of the amount of coronal material flowing into interplanetary space in streamers or otherwise cannot readily account for atom densities recently derived for the Earth's neighbourhood [98]. On the other hand it is possible to account for the proposed high interplanetary density by considering the whole of interplanetary space (within I A.U.) as an extended corona [99]. Since many phenomena depend on $\mathrm{N}_{e}^{2}$ rather than $N_{e}$, it becomes necessary to determine the inhomogeneity of the corona in order to interpret measured mean values of $N_{e}[95,100,101,102]$. A doubt is cast on the electron nature of coronal scattering by a measurement of polarization showing a deviation as much as $35^{\circ}$ from tangential [ro3]. Quantitative changes of the corona with the sunspot cycle have been investigated [102, 104, 105].

There is additional evidence that coronal streamers represent the sources of recurrent geomagnetic storms [roz] but this is offset by the observation [06] that the outstanding streamer of the I952 eclipse occurred in the wrong hemisphere. The slope of coronal streamers is likely to represent the slope of the Sun's general magnetic field, and this implies that the field is being drawn outward by moving material [102]. Evidences on accretion effects are strongly negative [106]. 


\section{COUCHES EXTERIEURES DU SOLEIL}

Some new coronal lines have been detected [107] but these are not identified. All evidence now shows that the lines $\lambda 5446$ and $\lambda 5694$ are due to $\mathrm{Ca} \mathrm{XV}[108,109]$.

There are still discrepancies resulting from the various methods of determining the coronal temperature. Line broadening measurements $[110,11,112]$ continue to lead to $2000000^{\circ} \mathrm{K}$ or more. Temperature estimates based on the degree of ionization are generally less than $\mathrm{I} 000000^{\circ} \mathrm{K}$. However these are dependent on calculated ionization cross sections and some independent calculations [113] have led to $2000000^{\circ} \mathrm{K}$. In excited regions the ionization temperature is consistently above $2000000^{\circ} \mathrm{K}$ [91, iro, 114]. A recent radio model [155] suggested a temperature of $3000000^{\circ} \mathrm{K}$ which is much higher than that usually derived from radio. A density-gradient temperature of $\mathrm{I} 800000^{\circ} \mathrm{K}$ has also been derived [110].

The condensations, or high excitation areas, of the corona play a part in solar emission problems that is somewhat analogous to the part played by plages and faculae of the chromosphere. Recent researches show: that the condensations emit X-rays [116]; that they have the same mean lives as faculae [117] and that they are associated with $\lambda 5^{6} 64$ radiation [9x].

\section{REQUESTS AND SUGGESTIONS TO BE CONSIDERED}

I. L'Observatoire de Meudon requests that the annual subvention of 2700 gold francs, agreed since 1925 by the I.A.U. for the publication of Cartes Synoptiques de la Chromosphère Solaire, should be renewed until the next assembly.

2. Waldmeier and Abetti propose a new discussion on the co-ordination of coronal observations. The aim should be to settle on methods whereby homogeneous measurements can be expected.

3. The McMath-Hulbert Observatory calls for a new name for 'Ellerman H-bombs' and 'moustaches'. A word that compares with 'flare' and is reasonably descriptive of the phenomenon is 'spark'.

4. Öhman recommends timing coronal prominences in white light and $\mathrm{H} \alpha$. Real condensations should appear first in white light. He also recommends spectrographic investigations of condensation to test the temperature.

5. Ohman recommends a study of the Fraunhofer lines appearing in the continuous spectrum of prominences to derive velocities of free electrons. The lines should be $20 \AA$ wide.

6. Abetti offers the opinion that the Fraunhofer Institut solar diagrams are the best available. Other institutions should copy them or co-operate by sending information to Freibourg.

7. The Royal Observatory of Belgium, Uccle, asks that the first results of I.G.Y. co-operation (including the question of Ursigram, reports, $24 \mathrm{~h}$ flare and chromospheric patrol) be discussed at Moscow.

8. The Observatory at Uccle also draws attention to the necessity of obtaining homogeneous descriptive scales for solar phenomena so that definitive scales may be established after the I.G.Y. It is noted that there is not yet an agreed solar activity index [n8]. A shape code for flares might be introduced.

\section{BOOKS}

The following books dealing with the Sun's outer layers have appeared:

Physik der Sternatmosphären, and ed. by A. Unsöld.

Ergebnisse und Probleme der Sonnenforschung, and ed. by M. Waldmeier.

The Sun, English translation by J. B. Sidgwick of book by G. Abetti.

The Sun and its Influence, by M. A. Ellison.

Die Sonnenkorona II, by M. Waldmeier.

We might also call attention to the Astrophysics section of the forthcoming Handbuch der Physik of which vol. 52 contains an article on the Sun's atmosphere by C. de Jager. 


\section{COMMISSION 11}

\section{REFERENCES}

[I] Roberts, W. O. 9th Report on Solar-Terr. Relations, 1957.

[2] Solc, I. Czech. J. Phys. 4, I, 1954.

[3] Öhman, Y. Stockholm Obs. Ann. 19, no. 4, 1956.

[4] Dollfus, A. Rev. d'Opt. 35, 539, 625, 1956.

[5] McMath, R. R. et al. Ap.J. 124, I, 1956.

[6] Mohler, O. C. and Pierce, A. K. Ap. J. 125, 285, 1957.

[7] Wlérick, G. and Axtell, J. $A p . J .126,253,1957$.

[8] Dollfus, A. See (I).

[9] Rush, J. H. See (I).

[10] Billings, D. E. et al. Astr. J. 62, 8, 1957.

[11] Karimov, M. G. and Moroz, V. I. C.R. Acad. Sci. U.R.S.S. rog, 469, 1956.

[12] Bulletin d'Information du C.S.A.G.I., nos. I-7, I953-56.

[13] Öhman, Y. Instruction Manual for Solar Activity, Ann. I.G.Y., 5, 249, 1957.

[14] Trans. I.A.U. 9, r37, 1957.

[15] Billings, D. E. and Varsavsky, C. M. $Z . A p .3^{8}$, I60, 1955.

[16] Bruzek, A. Z. Ap. 35, 213, 265, 1955.

[17] Dodson, H. W. McMath-Hulbert Obs. Repr. no. 4I, 1956.

[18] Kiepenheuer, K. O. and Deubner, F. L. Z. Ap. 45, I7, $195^{8}$.

[19] Michard, R. and Laborde, G. Ossvz. Oss. Astrofis. Arcetri, Contr. no. 3, I955

[20] Krat, V. A. and T. V. Pulkova Bull. 19, no. 153, I, I955; 20, no. I55, I, 1956.

[21] Parker, J. M. Ap. J. 121, 731, r955; Astr. J. 62, 29, I957.

[22] Athay, R. G., Smith, H. J. and E. v. P. Astr. J. 62, 2, 33, 1957.

[23] Redman, R. O. and Suemoto, Z. M.N. r14, 524, 1954.

[24] Kawaguchi, I. Publ. Astr. Soc. Jap. 5, 137, 1954.

[25] Michard, R. Ann. Astrophys. 19, I, 1956.

[26] Pecker, J.-C. and Athay, R. G. Ap. J. 121, 391, 1955.

[27] Thomas, D. V. 'Les molécules dans les astres', Liège, 264, 1957.

[28] Athay, R. G. et. al. Ap. J. 123, 285, 1956; Ap. J. Supp. 1, no. 12, 505, 1955.

[29] Miyamoto, S. Publ. Astr. Soc. Jap. 6, 229, 1954.

[30] Böhm-Vitense, E. Z. Ap. 36, 145, 1955.

[31] Namba, O. Publ. Astr. Soc. 6, 87, 1954.

[32] Jager, C. de. B.A.N. 13, 133, 275, 1957.

[33] Treanor, P. J. M.N. 117, 22, 1957.

[34] Macris, C. R.C. Accad. Lincei, Ser. 8, 21, 303, 419, 1956.

[35] Khokhlova, V. L. Publ. Crim. Ob. 17, I77, I957.

[36] Lippincott, S. L. Smithson. Contr. Astrophys. 2, I5, I957; Ann. Astrophys. 18, I13, 1955.

[37] Athay, R. G. and Thomas, R. N. $A p$. J. 123, 299, 309, 1956; 124, 586, 1956; 125, 788, 804, 1957; Ap. J. Supp. 1, no. 12, 491, 1955; Astr. J. 62, 3, 1957.

[38] Bishop, R. O. M.N. 116, 593, 1956.

[39] Thomas, R. N. Ap. J. 108, 142, 1948.

[40] Giovanelli, R. G. Aust. J. Sci. Res. 1, 275, 289, 305, 360, 1948.

[4 I] Matsushima, S. Ap. J. Supp. 1, no. 12, 479, 1955.

[42] Pecker, C. and Pecker, J.-C. Contr. Inst. Astrophys., Paris, no. A 213, 1956.

[43] Jefferies, J. T. (and Giovanelli, R. G.) Aust. J. Phys. 7, 574, 1954; 8, 335, 1955.

[44] Oster, L. Z. $A p .40,28,1956$.

[45] Plaskett, H. H. M.N. 116, 419, 1956.

[46] Nagasawa, S. Publ. Astr. Soc. Jap. 7, 9, 1955.

[47] Ellison, M. A. 9th Report on Solar-Terr. Relations, 1957.

[48] Severny, A. B. A.Zh. 33, 74, 1956; Observatory, 76, 24I, 1956; Iz. Krim. A. Ob. 17, 129, 1957.

[49] Mustel, E. R. Iz. Krim. A. Ob. x5, 54, 95, 1955; Gordon, I. M. Dopovidi Ak. Nak. no. I, I3, 1954 .

[50] Severny, A. B. and Mustel, E. R. Iz. Krim. A.Ob. 13, 82, 1955. 


\section{COUCHES EXTERIEURES DU SOLEIL}

[51] Bruzek, A. Z. Ap. 38, 1, 1955.

[52] Severny, A. B. and Saposnikova, E. F. A. Zh. 31, I24, I954.

[53] Dodson, H. W. et. al. Ap. J. Supp. 2, 24x, 1956.

[54] Warwick, J. W. Ap. J. 121, 376, 1955.

[55] Warwick, C. S. $A p . J$. 120, 237, 1954; 121, 385, 1955.

[56] Razmadze, T. S. Bull. Abastumani. A. Ob. no. 16, 59, 1954.

[57] Svestka, Z. and Fritzová, L. Bull. Astr. Insts. Czech. 7, 9, 30, 130, 1956; 8, 61, 1957. Publ. Astr. Inst. Czech. no. 32, 1957.

[58] Trotter, D. E. and Roberts, W. O. Reports High Alt. Ob. Colorado, from 1953.

[59] Chubb, T. A. et. al. J. Geophys. Res. 62, 389, 1957.

[60] Notuki, M. et. al. Publ. Astr. Soc. Jap. 8, 52, 1956.

[6I] Zirin, H. Ap. J. 126, I59, 1957.

[62] Roberts, W. O. and Billings, D. E. A. Astr. J. 60, 176, 1955.

[63] Piddington, J. H. Observatory, 76, 21, 1956; M.N. 116, 314, 1956.

[64] Sweet, P. A. Conferences. Electromag. phenom. Stockholm in 1956; Cosmic Rays Varenna in 1957.

[65] Bumba, V. Iz. Krim. A. Ob. 19, 105, 1957.

[66] Fermi, E. Phys. Rev. 75, I 169, 1949.

[67] Parker, E. N. Phys. Rev. 107, 830, 1957.

[68] Zuikov, V. N. Pulkova Bull. 20, no. I55, 22, 1956.

[69] Ellison, M. A. and Reid, J. H. Publ. R. Obs. Edinburgh, 2, 29, 1957.

[70] Ivanov-Cholodney, G. S. Iz. Krim. A. Ob. 13, II 2, I955; 15, 69, 1955.

[7I] Severny, A. B. A. Zh. 31, 131, 1954; Iz. Krim. A. Ob. 12, 33, 1954.

[72] Jefferies, J. T. M.N. 115, 617, 1955; 116, 629, 1956.

[73] Billings, D. E. and Zirin, H. Astr. J. 60, 155, 1955.

[74] Zirin, H. $A p . J .124,45 \mathrm{I}$, 1956.

[75] Idlis, G. M. et al. Iz. Ap. Inst. 2, 71, 1956.

[76] Ellison, M. A. M.N. II6, 624, 1956.

[77] Rothschild, K. et. al. Ap. J. r21, 224, 1955.

[78] Pettit, E. P.A.S.P. 67, 256, I955.

[79] Balkovoy, A. E. Iz. Krim. A. Ob. 16, 100, 1956.

[8o] Athay, R. G. and Orrall, F. Q. Ap.J. 126, 167, 1957.

[8I] Oster, L. Z. Ap. 36, $212,1955$.

[82] Lindgren, F. Stockholm Obs. Ann. 19, no. I 1, 3, 1957.

[83] Becker, V. $Z$. Ap. 40, 65, 1956; 42, I, 1957.

[84] Waldmeier, M. Z. Ap. 42, 34, 1957.

[85] Correll, M. et. al. Ap. J. 124, 597, 1956.

[86] Billings, D. E. P.A.S.P. 69, 162, I957.

[87] Kleczek, J. Bull. Astr. Insts. Czech. 8, 120, 1957.

[88] Dubov, E. E. Iz. Krim. A. Ob. 15, I21, 1955.

[89] Marshall, I. $A p . J .126, \mathrm{r} 77,1957$.

[9o] Öhman, Y. Ark. Astr. 2, I, 1957.

[91] Waldmeier, M. $Z . A p .38,125,219,1956 ; 39,219,1956 ; 40,221,1956$.

[92] Blackwell, D. E. M.N. 115, 629, 1955; 116, 56, 1956.

[93] Michard, R. et. al. Ann. Astrophys. 17, 320, 429, 1954; 19, 229, 1956.

[94] Allen, C. W. M.N. I16, 69, 413, 1956.

[95] Nadubovitch, J. A. $A, Z h .33,893,1956$.

[96] Hepburn, N. Ap. J. 122, 445, 1955.

[97] van de Hulst, H. C. B.A.N. Ir, I35, I950.

[98] Piggott, W. R. and Allen, C. W. 9th Report on Solar-Terr. Relations, 1957.

[99] Chapman, S. Smithson Contr. Astrophys. 2, I, 1957.

[10o] Jorand, M. Ann. Astrophys. 18, I80, 1955.

[IOI] Vitkevich, V. V. A. Zh. 33, 62, r956.

[102] Nikolsky, G. M. A. Zh. 33, 84, 87, 588, 1956.

[103] Newkirk, G. et. al. Astr. J. 62, 95, 1957. 


\section{COMMISSION 11}

[104] Abbott, W. N. Ann. Astrophys. 18, 81, 1955.

[105] Bugoslavskaya, E. Y. A. Zh. 34, 233, 1957.

[106] Blackwell, D. E. and Dewhirst, D. W. M.N. 116, 637, 1956.

[107] Aly, M. K. $A p . J$. 122, 438, 1955.

[108] Rohrlich, L. Ap. J. I23, 521, 1956.

[109] Pecker, C. et. al. Ap. J. 120, 509, 1954.

[110] Billings, D. E. et. al. Ap. J. 123, 532, 1956; 125, 817, 1957; Z. Ap. 43, 218, 1957.

[III] Jarrett, A. H. and Klüber, H. von. M.N. II5, 343, I955.

[I I 2] Karimov, M. I. and Obasher, C. O. Iz. Ap. Inst. 5, 66, 73, 1957.

[113] Werner, Alma, Aust. J. Phys. 7, 25, 1954.

[1 14$]$ Kleczek, J. Bull. Astr. Insts. Czech. 8, 68, 1957.

[115] Panovkin, B. N. A. Zh. 34, 505, 1957.

[1 I6] Elwert, G. Z. Ap. 41, 67, 1956.

[II 7] Bruzek, A. Z. Ap. 35, $213,265,1955$.

[I18] Beynon, W. J. G. and Brown, G. M. J. atmos. terr. Phys. II, I28, 1957.

\section{1a. SUB-COMMISSION ON CINEMATOGRAPHY OF CHROMOSPHERIC PHENOMENA}

The principal task entrusted to the Sub-Commission at the Dublin meeting was that of preparing a Working Commission Report giving a working manual of operating standards for solar flare patrols in $\mathrm{H} \alpha$, and embracing a suggested list of participating observatories to engage in a co-operative patrol on a 24 -hours per day basis. That task has been met by the report appended.

The further task of reaching a decision about centralization of films and data from the flare patrols was not directly approached by the sub-commission, or its working committee, and remains for final resolution at the Tenth General Assembly. However, recommendations and agreements reached among I.G.Y. committees have put into effective operation a programme of data centralization, which has improved availability of the greatly extended flare observations now being made.

An additional task, moreover, must be faced by the Sub-Commission at the coming meeting: to make a recommendation regarding the long-standing goal of Commission Ir to recommend the production of a continuous, uninterrupted, co-operative film of chromospheric activity of the solar disk in $\mathrm{H} \alpha$.

\section{Suggestions and Recommendations}

As we face the Moscow meeting, two different viewpoints exist within the Sub-Commission regarding the feasibility of preparing such a co-operative solar film:

(I) D'Azambuja proposes that the time has come to realize what has constituted the essential task of Commission I $a$, namely to obtain such a continuous film from the start to the finish of one or more series of events constituting an unbroken continuity of observations perhaps of several days' duration.

D'Azambuja further proposes that original films, rigorously standardized, be utilized in this enterprise, and that they be centralized, after preparation by the original observatory, for preparation of positive copies for final editing.

(2) McMath, on the other hand, recommends that the project of preparing a continuous edited copy of chromospheric motion pictures, for extended periods of time (months or years), combining the results of the various photographic flare patrols that are in operation on reasonably uniform standards throughout the world, be dropped.

McMath argues that the project will be too expensive in terms of the time it will take from research of first-rate astronomical talent, that the film will probably not be produced quickly enough to keep abreast of the demands of current research, and that the usefulness 


\title{
COUCHES EXTERIEURES DU SOLEIL
}

of the film will depend chiefly on a detailed record of the observations that should accompany the film, and without which it will be useless for research.

As an alternative, McMath proposes that financial support be sought for preparation and publication of a detailed catalogue of solar sequences photographed by participating observatories, and that support be sought for shipment of films to investigators who have specific research interests, and that funds for travel of investigators be obtained if it is thought advisable not to ship films.

Several members of the Sub-Commission have not expressed views on this problem; thus it should receive careful attention at the tenth General Assembly.

Additional recommendations and comments have been made as follows:

(a) McMath calls attention of the Sub-Commission to the fact that recent improvements in diffraction gratings make possible new spectroheliographs of much greater precision and flexibility than other existing instruments for the observation of the chromosphere, and recommends their consideration in designing instruments for precise chromospheric cinematography.

(b) McMath also points out that an urgently needed form of cinematographic observation is a series of spectroheliograms showing changes in transient chromospheric phenomena as functions of time and wave-length through a small wave-length range $( \pm 4 \AA)$ of precisely determined wave-length, including a strong chromospheric line, such as $\mathrm{H} \alpha, \mathrm{K}$, etc.

(c) Waldmeier recommends a modification of the former recommendation for image diameter on flare patrols. He recommends the use of an image of 20-22 mm diameter, with the polar calottes of the Sun cut off. The gain in resolution, Waldmeier suggests, fully justifies loss of this picture area in which flares are not found.

(d) Roberts recommends that more attention be given to fast-rate, high-magnification cinematography of spicules, and of internal details of large prominences with high resolution telescopes of 12 -inch to 15 -inch aperture, in view of the excellent results recently obtained at Sacramento Peak Observatory by such techniques. Similarly, cinematography of emission coronal details, pioneered by Lyot, now deserves special attention because of the evidences on Sacramento Peak films of spectacular coronal motions in unusual instances.

(e) Abetti recommends that some decision should be made on a method of collecting and studying cinematograph records obtained in various observatories, as described in Trans. I.A.U. 9, 157 .

$(f)$ Severny wishes to stress the importance of continuous $\mathrm{H} \alpha$ solar disk patrol, from sunrise to sunset, at the times when signals of an artificial satellite may be obtained from its radio transmitter. Roberts concurs in emphasizing the importance of such observations to analysis of ionospheric effects on $20 \mathrm{Mc} / \mathrm{s}$ artificial satellite signals.

\author{
W. O. ROBERTS \\ President of the Sub-Commission
}

\section{APPENDIX}

\section{REPORT OF THE WORHING COMMITTEE}

\section{Introduction}

At the meeting of Commission II $a$ on I September 1955, a Working Committee was appointed consisting of the following members: Roberts, L. d'Azambuja, Dodson, Severny, Coutrez, Kiepenheuer, and Öhman.

The Committee was charged with responsibility to 'recommend uniform standards of film characteristics, photometric procedures, and to arrange reporting schedules' for a continuous photographic $\mathrm{H} \alpha$ patrol of the solar disk. The final product of the Committee's work was to be an operating manual for distribution to participating observatories. 


\section{COMMISSION 11}

The following pages, therefore, are intended as a manual describing the procedures recommended for uniform adoption for routine photographic $\mathrm{H} \alpha$ flare patrols to be operated by participating observatories from I July 1957, the start of the I.G.Y., until 3I December I958, the end of the I.G.Y.

At a later date we will distribute a recommendation for centralization of the flare data by participating observatories.

\section{Manual of operating standards}

The following operating standards are specified as the minimum requirements held desirable by the Working Committee for all observatories participating in the continuous I.G.Y. photographic $\mathrm{H} \alpha$ flare patrol. It should be emphasized, however, that flare observations not meeting these standards may nevertheless be of great value during the I.G.Y. Specifically the Working Committee wishes to call attention to the great value of high-quality visual patrol observations of solar flares, such as those reported for many years to the I.A.U. Quarterly Bulletin via the Meudon Observatory, which should be continued and expanded during the I.G.Y. The rapidity with which visual patrol observations can be made available is a particular value of such observations and, therefore, it is desirable whenever possible that a visual patrol be carried on simultaneously with the photographic one.

It is also desirable that observatories taking part in the photographic patrol report exceptional events, such as 3 or $3^{+}$flares, etc., even if these appear at times other than those designated for the observatory.

Observations of flares in the $\mathrm{H}$ or $\mathrm{K}$ lines of calcium are also of considerable importance during the I.G.Y. and should be encouraged, even though standards for such observations are not a responsibility of this Working Committee.

\section{A. General standards}

I. In accordance with the actions of the (Rome) I952 Assembly of the I.A.U. (Trans. I.A.U. 8, $\mathrm{I}_{52}$ ) the recommended photospheric solar image diameter for the proposed co-operative cinematographic patrol of the chromosphere will be $15 \mathrm{~mm}$ when the SunEarth distance is I A.U. Some co-operating observatories, however, strongly prefer different image sizes, in the range from $\mathrm{I}_{4}$ to $22 \mathrm{~mm}$. It seems desirable, therefore, to recommend the $15 \mathrm{~mm}$ image size, but to specify a range of acceptable sizes from 14 to $22 \mathrm{~mm}$. All records shall be taken cinematographically on $35 \mathrm{~mm}$ film, with images covering the whole solar disk, or at least the zones within which all flares can be expected to occur.

2. Participating observatories will cover the agreed periods of observing on all days when the sky is sufficiently clear for obtaining correctly exposed images of good quality. Intervals between pictures should not exceed $3 \mathrm{~min}$. A preferred rate is that adopted by Commission II $a$ in I952 (Trans. I.A.U. 9, I52) of one picture every $30 \mathrm{sec}$; particularly is this faster rate recommended for adoption on World Days of the I.G.Y.

Coverage of additional hours by participating observatories is also highly desirable.

3. Every $30 \mathrm{~min}$ a frame will be added to the patrol films with exposures increased sufficiently to record limb prominences, but with no change in the band-pass of the filter. It is suggested as desirable, but optional, for observatories whose filters have line shifters to add, every hour, a series of frames covering in five or more different steps the different parts of the $\mathrm{H} \alpha$ line from the red wing to the blue wing, with no change in the filter band-pass.

4. The over-all optical systems shall have a resolution of better than two seconds of arc.

\section{B. Bi-refringent filter standards}

I. H $\alpha$ images will be obtained through bi-refringent filters, with band-pass (band-width at half-intensity) preferably of $0.75 \AA$. However, films will be acceptable from good quality filters with band pass between 0.5 and $I \cdot 2 \AA$. The appearance of the images 


\section{COUCHES EXTERIEURES DU SOLEIL}

changes very materially with small changes of band-width, and widths greater than $0.85 \AA$ should be avoided if possible.

2. Temperature control shall be sufficient to maintain the peak transmission at the normal position of $\mathrm{H} \alpha+0 . \mathrm{I} \AA$ for $\mathrm{a} \mathrm{I}^{\circ} \mathrm{O} \AA$ band half-width or $\pm 0.05 \AA$ for a filter of $0.5 \AA$.

3. The optical systems shall be such that the extreme rays through the filters shall not depart from the normal position of $\mathrm{H} \alpha$ by an amount exceeding $0.2 \AA$ for a $\mathrm{I} \AA$ filter or $0.1 \AA$ for a filter of $0.5 \AA$.

4. The prototype filters for the flare patrols shall be the Lyot-designed filters of $0.75 \AA$ band-pass manufactured by Optique et Precision de Levallois Paris. For these filters the Meudon Observatory has agreed to guarantee the performance to equal the established specifications given by the manufacturer.

\section{Film and photometric standards}

I. The recommended film shall be similar to Eastman Kodak Type IV-E (with grey anti-halation film base) processed in D-76, or a weakened $M Q$ developer, somewhat below the recommended development time $\left(7-8 \mathrm{~min}\right.$ at $\left.18^{\circ} \mathrm{C}\right)$ to give a gamma of about 2.0 or even a bit lower. This is a relatively contrasty film of moderate speed and good grain characteristics. The Working Committee has received assurances from Eastman Kodak Company that adequate supplies of the Type IV-E emulsion can be made available, providing the needed amounts can be estimated several months beforehand. Other similar films will, of course, be acceptable, and may be more desirable at certain of the co-operating observatories. (Suggested alternative films are Kodak Limited 6014 from England, and Panchromatic 800 from the U.S.S.R.). Some observers will prefer clear base film, which will also be acceptable.

The normal disk background density at the centre of the solar disk recommended is 0.5 above background. Some observatories may prefer a slightly lower central disk density. Exposures will, of course, have to be adjusted with changes in sky and Sun altitude.

2. Minimum photometric calibrations shall consist of the following:

(a) Photometric standards shall be placed at the start of each film run, and also at the end, if possible. Added standards within the film runs are highly to be recommended, if they can be provided.

(b) The standards shall consist of the following: (i) successive frames, at normal exposure, of the solar disk through graded density filters, with not less than five steps between density 0 and density $I \cdot 0$; (ii) a frame, with no neutral filter, at $2 \times$ normal exposure; and (iii) a frame, with no neutral filter, at $4 \times$ normal exposure. For these latter frames account will have to be taken of reciprocity failure.

Alternatively, an acceptable procedure is to impress on the film standards from a diffuse sunlight source (filtered by suitable broad-band filters so that the $\mathrm{H} \alpha$ wave-length is approximated) illuminating a step wedge that is imaged on the film, by-passing the bi-refringent filter. This procedure will doubtless be preferred by some observatories.

(c) Diffusely scattered light in the optical system, including filter, shall be measured periodically, if possible. (This is not considered an 'essential' but a 'desirable' specification.) A recommended simple procedure is to measure the background density just beyond the solar disk, on a day when the sky is very clear and dust-free, on exposures sufficiently long to bring the background density to a level comparable with the normal disk. The background intensity can, in such circumstances, be considered to represent the diffusely scattered light in the optical system.

(d) The contrast factor (the integrated intensity of the principal transmission peak compared to the integrated intensity transmitted for all other effective wave-lengths) shall be determined. One way to do this is to compare the disk image density with the filter centred on $\mathrm{H} \alpha$, with that when the filter is de-tuned sufficiently far to be away from the line wings in a spectral region of the continuum free of absorption lines (the transmission profile of the filter must be assumed to be known for this determination). 


\section{COMMISSION 11}

(e) The transmission profile of each filter used at a participating observatory shall, if possible, be determined experimentally. A number of alternative procedures for determining these quantities are possible, and some, particularly spectrographic methods, may be preferable. The effect of film halation cannot be overlooked in determination of flare intensities, from such flare patrol observation. We recommend a grey anti-halation base as a compromise between the serious halation effects on clear film, and the substantial problems encountered in processing the black-antihalation backing manufactured by Eastman Kodak Company.

$(f)$ Alternative procedure for steps $(b),(c)$ and $(d)$ may be found preferable at given observatories. The above suggestions are intended as guides for minimal specifications only. More elegant techniques are possible and will, most likely, be preferred in many observatories.

3. It is recommended that observers who have visual flare photometers make measurements as nearly as possible at the times of their photographic recordings in order to ascertain that consistent determinations are made.

\section{Suggested List of Participating Observatories and Schedules}

(a) 21 March-21 September

\begin{tabular}{|c|c|}
\hline U.T. hours & Stations \\
\hline $0-2$ & $\begin{array}{l}\text { Tokyo } \\
\text { C.S.I.R.O. Australia }\end{array}$ \\
\hline $2-4$ & $\begin{array}{l}\text { Tokyo } \\
\text { C.S.I.R.O. Australia } \\
\text { Kodaikanal }\end{array}$ \\
\hline 4-6 & $\begin{array}{l}\text { Tokyo } \\
\text { Kodaikanal }\end{array}$ \\
\hline $6-8$ & $\begin{array}{l}\text { Meudon } \\
\text { Switzerland } \\
\text { Capri, German Station } \\
\text { Istanbul } \\
\text { Cape of Good Hope }\end{array}$ \\
\hline $8-10$ & $\begin{array}{l}\text { Meudon } \\
\text { Capri, Swedish Astrophysica } \\
\text { Station } \\
\text { Arcetri } \\
\text { Uccle }\end{array}$ \\
\hline $10-12$ & $\begin{array}{l}\text { Ebro Observatory } \\
\text { Uccle } \\
\text { Nederhorst }\end{array}$ \\
\hline $11-14$ & $\begin{array}{l}\text { Ottawa } \\
\text { Crimean Astrophysical }\end{array}$ \\
\hline $12-14$ & $\begin{array}{l}\text { Ottawa } \\
\text { Naval Res. Lab. U.S.A. } \\
\text { McMath-Hulbert }\end{array}$ \\
\hline $14-16$ & $\begin{array}{l}\text { McMath-Hulbert } \\
\text { Sacramento Peak } \\
\text { High Alt. Obs. } \\
\text { San Miguel }\end{array}$ \\
\hline $15-17$ & $\begin{array}{l}\text { R.G.O., Herstmonceux (to } \\
18^{\text {b }} \text { from } 1 \text { May to } \\
31 \text { August) }\end{array}$ \\
\hline $16-18$ & $\begin{array}{l}\text { McMath-Hulbert } \\
\text { Sacramento Peak } \\
\text { High Alt. Obs. }\end{array}$ \\
\hline
\end{tabular}

(b) 22 September-20 March

\begin{tabular}{cl} 
U.T. hours & \multicolumn{1}{c}{ Stations } \\
$0-2$ & Tokyo \\
& C.S.I.R.O. Australia \\
$2-4$ & Tokyo \\
& C.S.I.R.O. Australia \\
& Kodaikanal \\
$4-6$ & C.S.I.R.O. Australia \\
& Kodaikanal \\
$6-8$ & Switzerland \\
& Capri, German Station \\
& Kodaikanal \\
& Cape of Good Hope \\
& Meudon \\
$8-10$ & Capri, Swedish Astrophysical \\
& Station \\
& Uccle \\
& Arcetri \\
& Istanbul \\
$10-12$ & Ebro Observatory \\
& Uccle \\
$10-13$ & Nederhorst \\
& Crimean Astrophysical
\end{tabular}

12-14 Ottawa

Naval Res. Lab. U.S.A.

Cape of Good Hope

14-16 McMath-Hulbert

Naval Res. Lab. U.S.A.

San Miguel

$\begin{array}{ll}\text { 16-18 } & \text { McMath-Hulbert } \\ & \text { Sacramento Peak } \\ & \text { High Alt. Obs. }\end{array}$




\section{COUCHES EXTERIEURES DU SOLEIL}

\section{Suggested List of Participating Observatories and Schedules (cont.)}

(a) 2 I March-2I September

\begin{tabular}{ll} 
u.T. hours & \multicolumn{1}{c}{ Stations } \\
18-20 & Sacramento Peak \\
& High Alt. Obs. \\
& Mount Wilson \\
20-22 & Sacramento Peak \\
& High Alt. Obs. \\
& Mount Wilson \\
& Hawaii \\
22-24 & Sacramento Peak \\
& High Alt. Obs. \\
& Mount Wilson \\
& Hawaii \\
& Tokyo \\
& New Zealand
\end{tabular}

(b) 22 September-20 March

\begin{tabular}{cl} 
U.T. hours & \multicolumn{1}{c}{ Stations } \\
18-20 & Sacramento Peak \\
& High Alt. Obs. \\
& Mount Wilson \\
20-22 & Sacramento Peak \\
& High Alt. Obs. \\
& Mount Wilson \\
& Hawaii \\
22-24 & Hawaii \\
& C.S.I.R.O. Australia \\
& Mount Wilson \\
& New Zealand
\end{tabular}

Additions or corrections to the above list will be appreciated by the Working Committee, and should be addressed to the Chairman, Dr Walter Orr Roberts, High Altitude Observatory, Boulder, Colorado, U.S.A.

Report of Meeting. I5 August $195^{8}$

President: C. W. Allen.

SECRETARY: M. A. Ellison.

The President began by referring to the death of Prof. M. N. Saha.

The Draft Report was accepted without essential changes. Matters referred to in the report of the Dublin Meeting appeared to have been adequately covered by the I.G.Y. programme.

The probable future of the Commission arising out of the Unsöld-Greenstein memorandum was explained.

Professor Ohman reported briefly on the I.G.Y. programme in solar activity. The meeting was informed of the continuation of the I.G.Y. programme in I959 and opinion was expressed that the present scheme of selected solar data centres should be continued.

After a short discussion the Commission resolved to recommend that the annual subvention of 2700 gold francs, agreed since r 925 by the I.A.U. for the publication of the Cartes synoptiques de la chromosphère solaire, should be renewed to the Meudon Observatory until the next General Assembly.

The President then referred to some correspondence he had had with the General Secretary in relation to 'the study of the problem of co-ordination of routine solar observations in order to avoid unnecessary duplication in the future'. It was resolved that this Commission recognizes the great value of long-established solar observations by several institutions and hopes that these may continue. In the event of a set of observations being brought to a close it was recommended that corresponding observations should be established in their place and that there should be an adequate period of overlap. It was felt that this matter should be referred to the new Commission ro.

The proposal for the co-ordination of coronal observations put forward by Waldmeier and Abetti was referred to Commission II $a$. It was agreed that the I.G.Y. was handling the question of homogeneous descriptive scales for solar phenomena.

Dr d'Azambuja reported on the progress of the coronameter. 


\section{COMMISSION 11}

The four terms-bombs, moustaches, sparks and points (referring to the same phenomenon)-were discussed. It was agreed to drop the term 'bomb', and to retain for the present the other three.

Ohman spoke briefly on his observational recommendations 4 and 5 quoted in the Draft Report.

Vitkevich spoke on radio observations of the occultations of the Taurus A source by the solar corona.

\section{Report of Meeting of Sub-Commission II $a$. I8 August I958}

President: W. O. Roberts.

Secretary: A. B. Severny.

\section{APPROVAL OF WORKING COMMITTEE REPORT}

The President expressed thanks to all who participated in compiling the report of the working committee, and expressed the hope that procedures for intensity standardization of flare patrol observations will be improved compared to present practise. He recommended approval of the working committee report and prolongation of fiare patrol observations according to these standards, to supplement observations of solar radio noise, sudden enhancements of atmospherics, sudden absorptions of cosmic noise, etc. Dr Ellison recommended that the intensity standardization of flare patrol films be extended to every frame. The Sub-Commission then adopted the following resolution:

The Sub-Commission accepts the Report of the Working Committee on Flare Patrols, and considers desirable the extension of the Working Committee for the period of the prolongation of I.G.Y.-level solar observations, for the purpose of preparing and distributing a schedule for sharing the observing load among participating observatories.

Dr Roberts then expressed sincere thanks to the Sub-Commission for the many years of faithful service of Dr d'Azambuja, who has now resigned from the Sub-Commission and the working committee, and recommended his replacement on the Sub-Commission by Dr J. Rösch. He also announced the appointment of Drs J. Rösch and R. Giovanelli to the Working Committee.

\section{CENTRALIZATION OF DATA AND FILMS OF FLARE PATROL}

The President pointed out that the existing system for centralization of solar data and films in I.G.Y. Data Centers was quite effective and should continue. He outlined briefly the hope that the data centers will publish a very complete catalog giving times and particulars of $\mathrm{H} \alpha$ patrol films. Dr Kiepenheuer recommended that such a catalog include estimates made by the original observatories of the quality of images and the defects of the negatives for each sequence. The following resolution was adopted:

The Sub-Commission endorses with satisfaction the I.G.Y. World Data Center programs of prompt and complete publication of flare patrol data and recommends their continuation in the period after I.G.Y. when intensive patrol work will be continued. It also recommends publication of the planned very complete catalog of available patrol films in $\mathrm{H} \alpha$ and other spectrum lines, and of data obtained by radio and other indirect means, as a reference source for future research. It recommends that notations of record quality be included in the catalog. 


\section{COUCHES EXTERIEURES DU SOLEIL}

\section{SPECIAL COMMITTEE FOR A CONTINUOUS FLARE FILM}

The President proposed the following resolution:

The Sub-Commission adopts as a goal for completion by the eleventh General Assembly the preparation at a central observatory of a continuous unbroken $24^{\mathrm{h}}$ cinematographic record, as accurately standardized as possible, of at least one 14 day period of carefully chosen high solar activity during the I.G.Y. This will involve use of original films by the centralizing agency, which will take great care to return the films in good condition. Copies will be made freely available at lowest possible cost to all requesting users. A special committee for a continuous flare film, consisting of Drs Henry Smith, R. Giovanelli, J. Rösch, and M. N. Gnevyshev, will be created to explore means of financing this task, and to supervise its completion. The recommendation of Dr Abetti (item (e), of Suggestions and Recommendations of the Sub-Commission Report) is specifically referred to this committee.

Dr d'Azambuja expressed agreement with the proposal, and stated the sincere hope the film would be of cinematic projection quality. Dr Mohler expressed general approval; but emphasized that the expense of the effort will depend on the excellence of the result demanded. In discussion it was agreed that gaps should be filled with films of quality not designed for cinematic reproduction only when absolutely necessary to avoid lacunae. The resolution was unanimously adopted.

\section{RECOMMENDATION ON FLARE PATROL IMAGE DIAMETER}

The proposal of Dr Waldmeier to adopt an image diameter of $20-22 \mathrm{~mm}$ for standard flare patrols was discussed. Dr Severny was against this proposal because it would demand serious reconstruction of many flare patrol instruments. After considerable discussion of image resolution, the problem of recording 'blow-off ' prominences, and related considerations, the Sub-Commission adopted the following resolution:

The Sub-Commission reaffirms the previously adopted recommendation (in the Report of the Working Committee on Flare Patrols) approving image diameters from $\mathrm{I}_{4}$ to $22 \mathrm{~mm}$, but recommending an image diameter of $15 \mathrm{~mm}$. The Sub-Commission, however, notes the advantages of using the larger images where possible, in view of the larger resolution thereby achieved.

\section{CONVENTION REGARDING ORIENTATION OF SOLAR IMAGES}

The following two resolutions were adopted:

(a) The Sub-Commission adopts the recommended convention of C.S.A.G.I. regarding the orientation of the solar image with heliographic north at the top and east at the left, and recommends its use, wherever possible, in preparation of copies of films or preparation of publications of photographs or diagrams of the solar disk.

(b) The Sub-Commission recommends that wherever it is not possible to place heliographic north at the top, the astronomical north position shall be placed at the top, with east to the left, and with the distinction between astronomical and heliographic coordinates clearly indicated.

\section{WORKING COMMITTEE ON CORONA STANDARDIZATION}

The problems of the distinctions between published coronal intensity data from different coronal stations referred to the Sub-Commission by the parent Commission was discussed at length. The need for standardization of intensity scales and heights for regularly published observations was emphasized. The following resolution was then adopted:

The Sub-Commission creates a working committee on coronal standardization to ascertain and recommend standard practices of coronal intensity standardization for emission and K-corona data publication. The members shall be as follows: Dr J. Rösch (Chairman), Drs M. N. Gnevyshev, R. Müller, G. Newkirk, M. Notuki, M. Waldmeier. 


\section{COMMISSION 11}

ORGANIZATION OF I.A.U. CONGRESS PUBLICATIONS AND MEETINGS

The President introduced a critical discussion of the work of the solar commissions, emphasizing that the functions of scientific review and of international agreements were sometimes badly confused and that the confusion may become even worse under the reorganized solar commission plans. He then introduced and recommended the following resolution:

The Sub-Commission strongly recommends that its functions of scientific review and of agreements for international cooperation shall be more clearly separated. It expresses the opinion that this problem extends to other commissions also. It recommends that the scientific reviews contained in the Transactions shall be selected syntheses prepared by the Presidents, and that the Transactions be divided into two volumes, one containing only the scientific information. It also recommends division of the meetings into separate scientific and business sessions. In the scientific sessions priority shall be given, at the discretion of the presidents, in the case of the outstanding developments, to presentations in this order:

(I) Invited syntheses of general nature, by announced speakers.

(2) Special invited contributions.

(3) Contributions submitted by title in advance of the meeting, for which printed summaries are available at the meeting.

(4) Other papers.

Dr Coutrez expressed the view that this was in accord generally with the recommendations of U.R.S.I. Dr Allen cautioned that the recommendation should go to the Executive Committee of the I.A.U. for consideration, since problems of commissions differed, and we cannot force all the commissions to go in the same line. Prof. Stratton pointed out that it is also difficult to select between meetings because two interesting commission meetings may run simultaneously.

After further discussion, the proposed resolution was unanimously adopted.

\section{APPROVAL OF DRAFT REPORT}

Items $(a),(b),(d)$ and $(f)$ of the Suggestions and Recommendations of the Sub-Commission Report were specifically approved. Thanks were expressed to Dr McMath for his contribution to this report.

Dr Kiepenheuer emphasized the need for synchronization of high resolution cinematography of solar limb phenomena with observations of radio bursts, particularly of Type Ir.

\section{MISCELLANEOUS RECOMMENDATIONS}

I. The expanding range of interests in cinematography in solar astronomy was discussed. Corona, prominence and filament cinematography are now in increasingly widespread practice. Dr Kiepenheuer recommended inclusion of white light cinematography of the photosphere under the Sub-Commission's interests. Dr Giovanelli also spoke in favor of white light observations by cinematography in spite of the great technical difficulties involved, and recommended that the Sub-Commission prepare for the next meeting a recommendation for a co-operative disk patrol of selected areas in white light. The SubCommission then informally approved Dr Allen's recommendation that its title be altered to become 'Sub-Commission on Cinematography of Solar Phenomena'.

2. Dr Popovich recommended that a new list of flare patrol participants be prepared, with the new observatories, like the Roumanian, included.

3. Drs Severny and Svestka recommended that attention be given to observation of flares in the ultra-violet. 